\title{
Zika: ¿catástrofe biológica mundial?
}

Loredo-Abdalá $\mathrm{A}^{1}$, Figueroa-Becerril $\mathrm{ZE}^{2}$, Vargas-Flores $\mathrm{J}^{2}$, Perea-Martínez $\mathrm{A}^{3}$, Arredondo-García JL ${ }^{4}$, Casas-Muñoz $\mathrm{A}^{1}$

\section{Resumen}

En el primer trimestre del año 2016 se ha informado una grave consecuencia en el producto in utero en mujeres embarazadas de Brasil, como resultado de la infección por el virus Zika. El desarrollo de microcefalia, así como daño variable en el sistema nervioso central y a nivel cardíaco ha llamado la atención de la Organización Mundial de la Salud, de las autoridades gubernamentales y de salud de los países latinoamericanos, de Estado Unidos y de países europeos, principalmente. Por este motivo, se ha puesto un mayor énfasis en la protección epidemiológica y personal de la población civil de países que viven en zonas tropicales y subtropicales del mundo, para evitar que sean contagiados por el virus Zika. Se ha puesto especial interés en las mujeres embarazadas y en aquellas que planean iniciar un embarazo y que pretenden visitar lugares de riesgo, así como en aquellas cuya pareja ha estado de viaje o permanecido en países tropicales.

PALABRAS CLAVE: Zika, microcefalia, daño cardíaco, mujer embarazada, actividad sexual.

Acta Pediatr Mex. 2016 Nov;37(6):341-348.

\section{Zika: global ecological catastrophe?}

Loredo-Abdalá $\mathrm{A}^{1}$, Figueroa-Becerril ZE², Vargas-Flores $\mathrm{J}^{2}$, Perea-Martínez $A^{3}$, Arredondo-García JL ${ }^{4}$, Casas-Muñoz $A^{1}$

\begin{abstract}
In the first quarter of 2016 it has been reported that pregnant women in Brazil, have had a serious consequence in their in utero product, caused by Zika virus infection. The development of microcephaly as well as serious damage to the central nervous and cardiac systems has strongly attracted the attention of the World Health Organization (WHO) government authorities and health of Latin American countries, US and European countries. For this reason greater emphasis has bean given to epidemiologic and personal protection of the civilian population of countries living in tropical and subtropical areas of the world, to avoid being infected by the Zika virus. Special interest has been in pregnant women and those planning to start a pregnancy; visit places of risk and the care they should have with their sexual activity, especially when their male partner has been away or stayed in those countries.
\end{abstract}

KEYWORDS: Zika; microcephaly; heart damage; pregnant women; sexual activity

\begin{abstract}
${ }^{1}$ Coordinador de la Coordinación de Estudios Avanzados sobre Maltrato Infantil/Prevención/Instituto Nacional de Pediatría. ( CEAMI/P/INP). Ex presidente y Académico titular de la Academia Mexicana de Pediatría A.C.

${ }^{2}$ Médico Pasante en Servicio Social. UNAM. Asignado a la Coordinación de Estudios Avanzados sobre Maltrato Infantil/Prevención/Instituto Nacional de Pediatría. (CEAMI/P/INP).

${ }^{3}$ Presidente de la Academia Mexicana de Pediatría A.C. Coordinador de la Clínica de Obesidad y de la Clínica para Adolescentes del Instituto Nacional de Pediatría.

${ }^{4}$ Sub Director de Investigación Médica del Instituto Nacional de Pediatría. Académico Titular de la Academia Mexicana de Pediatría A.C.
\end{abstract}

Recibido: 8 de marzo del 2016

Aceptado: 2 de septiembre del 2016

\section{Correspondencia \\ Arturo Loredo-Abdalá \\ cainm_inp@hotmail.com}

Este artículo debe citarse como Loredo-Abdalá A, Figueroa-Becerril ZE, VargasFlores J, Perea-Martínez A, Arredondo-García JL, Casas-Muñoz A. Zika: ¿catástrofe biológica mundial? Acta Pediatr Mex. 2016;37(6):341-348. 


\section{ANTECEDENTES}

En el primer trimestre de 2016 la Organización Mundial de la Salud (OMS) señaló que la epidemia de Zika debe considerarse como una "emergencia de salud pública" ya que afecta a casi todos los países de Centro y Sudamérica, principalmente Brasil y Colombia. También se han descrito casos en México, en Estados Unidos, algunos países de Europa y de Asía. ${ }^{1,2}$

El ataque de este virus se suma a los estragos en salud que han sufrido las poblaciones de los lugares mencionados por el dengue y el chikungunya. Sin embargo, a pesar que estos tres virus tienen un cuadro clínico muy similar, la diferencia con los dos primeros es el daño que ocurre en el producto de la gestación, cuando la madre es afectada por el virus de Zika. La consecuencia principal es microcefalia, cuya consecuencia en el sistema nervioso central no ha sido precisada en toda su magnitud.

Esta amenaza epidemiológica obliga a todo el personal de salud de nuestro país a conocer las consecuencias que esta infección puede ocasionar en las poblaciones de su entorno y por esta razón, la Organización Mundial de la Salud ha considerado la infección por el virus Zika como una amenaza de "proporciones alarmantes". 1,3

En el Cuadro 1 se presentan los países de América más afectados, así como las manifestaciones clínicas secundarias a la infección. Ante esta perspectiva, miembros de la Academia Mexicana de Pediatría A.C. y de la Coordinación de Estudios Avanzados sobre Maltrato Infantil/ Prevención del Instituto Nacional de Pediatría (CEAMI-P-INP) revisaron la literatura nacional e internacional sobre el tema, para presentar e insistir a la comunidad médica las características más importantes del agente causal, del vector, los daños descritos en los productos durante la gestación, las acciones requeridas en las mujeres embarazadas, las medidas sanitarias, ambientales que se deben establecer y los cuidados que las personas deben tener para evitar o disminuir las posibilidades de adquirir la infección.

\section{Características del virus}

El Zika es un virus ARN que se cataloga como un arbovirus, pertenece al género Flavivirus y a la familia Flaviviridae. ${ }^{4}$

\section{Características del agente transmisor}

La infección por el virus Zika se transmite por la picadura del mosquito Aedes aegypti, el cual se encuentra ampliamente distribuido en gran parte de Asia, África y la mayor parte de los países de América.

\section{Viabilidad del agente transmisor}

El vector se distribuye en forma permanente entre los $35^{\circ}$ de latitud norte y $35^{\circ}$ de latitud sur, pero puede extenderse hasta los $45^{\circ}$ norte y hasta los $40^{\circ}$ sur, donde coinciden con una temperatura de $10^{\circ} \mathrm{C}$ en verano. La altitud promedio en donde se encuentra es por debajo de los 1,200 metros sobre el nivel del mar. ${ }^{5}$

\section{MECANISMOS DE ADQUISICIÓN DEL VIRUS}

Está bien demostrado que el agente causal se transmite al ser humano a través de la picadura de los mosquitos hembra del género Aedes. El virus infecta el intestino medio del mosquito y luego se extiende hasta las glándulas salivales en un período de entre 8 y 12 días. Tras este período de incubación, el mosquito transmite el virus a las personas al picarlas con fines exploratorios o alimentarios.

Los mosquitos que propagan el virus del Zika pican agresivamente durante el día y pueden también picar por la noche. 
Cuadro 1. Características clínicas de casos de Zika en países de América

\begin{tabular}{|c|c|c|c|c|c|c|}
\hline País & $\begin{array}{l}\text { Casos totales } \\
\text { confirmados }\end{array}$ & $\begin{array}{c}\text { Casos en } \\
\text { embarazadas }\end{array}$ & $\begin{array}{l}\text { Malformaciones } \\
\text { congénitas }\end{array}$ & Guillain Barré & Defunciones & $\begin{array}{l}\text { Abortos } 0 \\
\text { mortinatos }\end{array}$ \\
\hline México & 1115 & 526 & 0 & 0 & 0 & 0 \\
\hline Estado Unidos & 1306 & 346 & 15 & 5 & 1 & 0 \\
\hline Honduras & 46 & 17 & 1 & $?$ & 3 & 0 \\
\hline Puerto Rico & 4427 & 553 & 1 & 14 & 1 & 0 \\
\hline Brasil & 64,311 & $?$ & 1,687 & $?$ & 4 & 102 \\
\hline Colombia & 8650 & 5,565 & 18 & 382 & 0 & 316 \\
\hline
\end{tabular}

Se reportan 40 países con transmisión autóctona; 5 países con transmisión sexual o de laboratorio: Argentina, Canadá, Chile, Estados Unidos, Perú.

Durante la primera semana de infección, el virus del Zika se puede encontrar en la sangre de la persona y pasar de la persona infectada a un mosquito si el insecto la pica. El mosquito infectado puede luego transmitir el virus a otras personas.

Otros mecanismos de transmisión son:

- A través del semen de una persona infectada y se ha documentado la transmisión de persona a persona por vía sexual en un caso. ${ }^{6}$

- La adquisición de la infección a través de una transfusión sanguínea de un donador infectado. ${ }^{?}$

- En la saliva se ha podido demostrar, por reacción en cadena de la polimerasa en tiempo real, la presencia de ARN del Zika, pero no se ha demostrado la replicación del virus. ${ }^{8}$

- No se ha precisado fehacientemente si el recién nacido puede adquirir el virus a través de la leche materna de una mujer infectada. En un estudio se ha detectado por reacción en cadena de la polimerasa el ARN de Zika en muestras de leche materna, aunque en otros estudios este fenómeno no se ha podido establecer. Sin embargo, si se ha detectado la eliminación de virus similares (dengue o del Nilo) por la leche materna. Es necesario que pase un período de tiempo razonable para que este fenómeno se confirme. ${ }^{9-11}$

\section{POBLACIÓN HUMANA SUSCEPTIBLE}

- Cualquier persona que viva en las zonas tropicales o subtropicales de casi todos los continentes del mundo. ${ }^{12}$

- Individuos que hayan estado de vacaciones o por períodos cortos de tiempo en las zonas detectadas como de alto riesgo para adquirir la infección.

\section{POBLACIÓN QUE REQUIERE VIGILANCIA ESTRECHA $^{13-14}$}

- Donantes potenciales que hayan viajado a zonas donde está presente la infección activa del Zika. Se ha planteado la necesidad de esperar 28 días para poder donar sangre.

\section{Población de alto riesgo}

- Mujeres embarazadas que viven en zonas consideradas de alto riesgo. 
- Mujeres que están tratando de quedar embarazadas y viven en zonas consideradas de alto riesgo.

- Mujeres no embarazadas cuyas parejas hombres se hayan infectado o bien que hayan viajado o vivan en una zona afectada por el virus Zika.

- Las mujeres embarazadas que han estado transitoriamente en zonas de riesgo deben estar bajo vigilancia durante 2-12 semanas.

- Mujeres embarazadas cuyas parejas hombres se hayan infectado o bien que hayan viajado o vivan en una zona afectada por el virus Zika.

Las consecuencias de la infección en el producto de la gestación se presentan en el Cuadro 2. Las lesiones anatómicas que se han desarrollado en el producto de la gestación cuando su madre ha sufrido la infección por el virus del Zica, tiene como órganos blanco el sistema nervioso central, los ojos y la placenta.

A. En el sistema nervioso central se ha observado la existencia de microcefalia, que se detecta clínicamente al momento de nacer como consecuencia de diversas alteraciones del tejido nervioso que se describen en el Cuadro 1. Si se presenta microcefalia después del nacimiento se denomina adquirida.
B. En los ojos el daño se caracteriza por una serie de alteraciones como se muestra en el Cuadro 1.

C. En la placenta se han descrito la presencia de calcificaciones y los Centers for Disease Control and Prevention ha reportado dos casos de aborto espontáneo y virus en las placentas.

D. Recientemente se ha observado, en algunos adultos infectados por el virus del Zika, una asociación con el síndrome de Guillain Barré. ${ }^{1}$ Esta patología se desarrolló en promedio al $6^{\circ}$ día de iniciada la infección por Zika en pacientes de la Polinesia Francesa. ${ }^{15}$

\section{MEDIDAS DE PREVENCIÓN Y PROTECCIÓN ${ }^{16}$}

Las medidas de prevención y protección que se deben establecer y mantener han sido precisadas por la Organización Mundial de la Salud; las más importantes son:

- Se puede realizar amniocentesis a las mujeres embarazadas que hayan viajado recientemente a una zona donde hay virus del Zika, que presenten dos o más síntomas dentro de las dos semanas después del viaje y que hayan tenido un resultado positivo o no concluyente en una prueba de suero materno.

- También se debe considerar la amniocentesis en mujeres embarazadas que

Cuadro 2. Características anatómicas y fisiopatológicas por infección del virus Zika

\begin{tabular}{|c|c|}
\hline $\begin{array}{l}\text { Daño en sistema } \\
\text { nervioso central }\end{array}$ & $\begin{array}{l}\text { Agyria, hidrocefalia, distrofia multifocal, calcificaciones de la corteza y materia blanca subcortical, } \\
\text { disgenesia del cuerpo calloso y vermiana, hipertrofia de la cisterna magna, ventriculomegalia unilateral } \\
\text { grave, agenesia del tálamo y discreta inflamación. } \\
\text { Clínicamente se manifiesta con microcefalia. }\end{array}$ \\
\hline Daño ocular & $\begin{array}{l}\text { Atrofia corio-retiniana del polo posterior del ojo y del área macular, daño del nervio óptico e hipoplasia } \\
\text { del mismo, ahuecamiento del disco óptico, manchas focales de pigmento, subluxación del cristalino, } \\
\text { cataratas y coloboma bilateral del iris. }\end{array}$ \\
\hline Daño placentario & Calcificaciones \\
\hline
\end{tabular}


hayan viajado recientemente a una zona donde existe el virus Zika y cuando un ultrasonido muestra datos de microcefalia o calcificaciones intracraneales en el feto.

- Tener en cuenta los riesgos y beneficios de este procedimiento. ${ }^{17}$

\section{Medidas generales para evitar el piquete del mosco Aedes aegypti ${ }^{18}$}

Mejorar las condiciones sanitarias ambientales:

a. Agua entubada.

b. Evitar charcas y recipientes que contenga agua de lluvias.

c. Fumigación constante y permanente de predios de zonas tropicales y subtropicales.

d. Fumigación de viviendas.

e. Uso de mosquiteros en puertas y ventanas.

f. Uso de mosquiteros en las camas.

g. Considerar, si es posible el uso de aire acondicionado.

Otras acciones domésticas:

a. Consumo constante de complejo vitamínico B.

b. Colocar sedimento de café en macetas, plantas y suelo. En el Perú se ha descrito que, dejando restos de café en las macetas, pisos y jardines, se reduce el tiempo de vida del mosquito adulto y bloquea el desarrollo de la larva en el segundo de sus cuatro estadios (datos no publicados).

Vestimenta de todos los habitantes de zonas de alto riesgo:

a. Utilizar ropa que cubra todo el cuerpo y las extremidades. b. Usar preferentemente ropa blanca o de color claro.

c. Se recomienda el uso rutinario de calcetines, calcetas y zapatos.

Medidas preventivas recomendadas en personas de alto riesgo

- Mujeres embarazadas cuyas parejas hombres hayan viajado o vivan en un área afectada por el virus Zika deben evitar las relaciones sexuales, o usar preservativo, hasta el término el embarazo. ${ }^{19-20}$

- Se recomienda que las mujeres embarazadas se abstengan de asistir a países que incluyan zonas en donde prolifere el mosquito Aedes aegypti para evitar adquirir la infección.

- Los hombres que hayan padecido la infección o que provengan de zonas potencialmente peligrosas no deben tener relaciones sexuales o, en su caso, usar el condón.

- No se sabe cuánto tiempo está presente el virus Zika en el semen de los hombres que han tenido la infección.

- La mujer embarazada debe evitar el saludo de beso o de mano a personas con la infección.

\section{Uso de productos protectores}

\section{a. Repelentes de insectos}

\section{Generalidades}

Seleccione y use repelentes de insectos registrados en la Agencia de Protección Ambiental (COFEPRIS). ${ }^{21}$

- Repelentes recomendados por la COFEPRIS: 
- Aceite de citronela (Cymbopogon nardus L.).

- Aceite de eucalipto de limón.

- Para-mentano-diol.

- Benzoato de bencilo.

- N,N-Dietil-m-toluamida

- (1-metil-propoxicarbonil)-2-(2hidroxietil)-piperidina.

- Siga siempre las instrucciones del producto señaladas por el fabricante.

- Repita la aplicación del repelente de insectos según las instrucciones.

- Cuando se usan los repelentes de acuerdo con las instrucciones del fabricante se ha comprobado que son seguros y eficaces, aun para las mujeres embarazadas y las que están amamantando.

- No se conoce la eficacia de los repelentes de insectos no registrados en la COFEPRIS, incluidos algunos repelentes vegetales.

Niños

- No use en niños productos que contengan más de $30 \%$ de N,N-Dietil-M-toluamida (DEET) ("OFF") o productos que contienen para-mentanodiol (versión sintética de eucalipto).

- No aplique repelentes de insectos a los bebés menores de dos meses.

- No aplique el repelente de insectos en las manos, los ojos, la boca, en la piel irritada o cortada del niño.

\section{Adultos}

- Primero aplíquese el repelente de insectos en las manos y luego al niño en la cara.
- Si usa filtro solar aplíqueselo antes del repelente de insectos.

\section{b. Otras medidas}

- Póngale a los niños ropa que les cubra los brazos y las piernas.

- Cubra la cuna, el cochecito y el porta bebé con un mosquitero.

- No aplique productos con permetrina directamente sobre la piel.

Estos productos son para tratar la ropa.

c. Fumigación ${ }^{21}$

- Fumigación de las zonas de riesgo y habitacional. El producto más recomendado para la fumigación es el DEET (N,N-DietilM-toluamida (OFF) a una concentración máxima de $40 \%$ en todos los tipos de aplicaciones.

- La fumigación seguida de la liberación controlada de mosquitos modificados genéticamente es una posibilidad para detener la propagación del virus de Zika (Organización Mundial de la Salud).

\section{d. Vacuna}

- No existe hasta el momento una vacuna activa.

\section{e. Otras estrategias}

Se está trabajando en el diseño de estrategias genéticas sobre la posibilidad de controlar las hembras, responsables de la picaduras, con la edición del genoma CRISPR-Cas9 y el gen Nix. Con esta acción dichas hembras, que son hematófagas y responsables de las picaduras, 
se convertirían en inofensivos machos que son succionadores de néctar. ${ }^{22}$

\section{DIAGNÓSTICO ${ }^{23}$}

\section{Clínico}

Los síntomas más comunes de la infección por el virus del Zika son: fiebre, exantema, dolor en las articulaciones y conjuntivitis. La enfermedad por lo general es leve con síntomas que duran varios días hasta una semana.

\section{Epidemiológico}

Personas sintomáticas que viven en casi todos los países de América, África y Asia, así como algunos países de Europa.

Personas asintomáticas que desarrollan el cuadro clínico dos semanas después de haber estado en algún país conocido por tener el virus Zika.

\section{Laboratorio}

Se realiza mediante reacción en cadena de la polimerasa (RT-PCR) que detecta la proteína no estructural 5 y aislamiento del virus en muestras de la sangre, en los primeros tres a cinco días del inicio de los síntomas. Sólo se realiza con fines de investigación. Después de cinco días se debe realizar diagnóstico serológico, detectar IgM a través de ELISA o inmunofluorescencia; el virus puede presentar reacciones cruzadas con otros flavivirus como los virus del dengue, del Nilo Occidental y de la fiebre amarilla. A las mujeres embarazadas se les puede practicar una determinación de IgM para detectar el virus del Zika.

\section{Gabinete}

Se puede efectuar ultrasonido a la mujer embarazada para tratar de demostrar la existencia de microcefalia en el producto; pero es posible que solamente se diagnostique al final del segundo trimestre o inicio del tercero.

En un informe publicado de dos bebés con ARN del virus del Zika establecido por reacción en cadena de la polimerasa se precisaron anomalías cerebrales mediante ultrasonido tales como: disgenesia del cuerpo calloso y disgenesia vermiana, hipertrofia de la cisterna magna, ventriculomegalia unilateral grave, agenesia del tálamo, cataratas y calcificaciones intracraneales e intraoculares.

Se desconoce el pronóstico para los bebés con infección congénita por el virus del Zika. Extrapolando las consecuencias de la microcefalia grave se han reportado una gran variedad de secuelas neurológicas tales como discapacidad intelectual, pérdida de la audición y la visión, crisis convulsivas. La severidad de estos problemas puede oscilar desde leves hasta graves, con frecuencia duran toda la vida y, en algunos casos, pueden ser mortales. ${ }^{24}$

\section{REFERENCIAS}

1. World Health Organization (WHO). WHO statement on the first meeting of the International Health Regulations (2005) (IHR 2005) Emergency Committee on Zika virus and observed increase in neurological disorders and neonatal malformations. Feb 1, 2016. (Fecha de consulta: Feb 24, 2016). Disponible en: http://www.who.int/ mediacentre/ news/statements/2016/1st-emergency-committee-zika/ en/.

2. Marcondes CB, Ximenes MFFM. Zika virus in Brazil and the danger of infestation by Aedes (Stegomyia) mosquitoes. Rev Soc Bras Med Trop. 2016;49(1):4-10. DOI: http://dx.doi. org/10.1590/0037-8682-0220-2015

3. Fauci AS, Morens DM. Zika Virus in the Americas - Yet Another Arbovirus Threat. N Engl J Med. 2016;374(7):601604. DOI: 10.1056/NEJMp1600297

4. Roa M. Zika virus outbreak: reproductive health and rights in Latin America. Lancet. 2016;387: 843. DOI: http://dx.doi. org/10.1016/

5. Centers for Disease Control and Prevention (CDC). Surveillance and Control of Aedes aegypti and Aedes albopictus in the United States. Feb 1, 2016. (Fecha de Consulta: Feb 24, 2016). Disponible en: http://www.cdc.gov/chikungunya/ resources/vector-control.html 
6. Oster AM, Brooks JT, Stryker JE, et al. Interim Guidelines for Prevention of Sexual Transmission of Zika VirusUnited States, 2016. MMWR Morb Mortal Wkly Rep 2016;65(5):120-121. DOI: http://dx.doi.org/10.15585/ mmwr.mm6505e1.

7. Musso D, Nhan T, Robin E, Roche $C$, Bierlaire D, Zisou K, Shan Yan A, Cao-Lormeau VM, Broult J. Potential for Zika virus transmission through blood transfusion demonstrated during an outbreak in French Polynesia, November 2013 to February 2014 . Euro Surveill 2014;19(14):pii=20761.

8. Lanciotti RS, Kosoy OL, Laven JJ, Velez JO, Lambert AJ, Johnson AJ, et al. Genetic and serologic properties of Zika virus associated with an epidemic, Yap State, Micronesia, 2007. Emerg Infect Dis. 2008;14(8):1232-9. DOI: 10.3201/ eid1408.080287

9. Besnard $\mathrm{M}$, Lastère $\mathrm{S}$, Teissier $\mathrm{A}$, Cao-Lormeau VM, Musso D. Evidence of perinatal transmission of Zika virus, French Polynesia, December 2013 and February 2014. Euro Surveill. 2014;19(13):pii=20751.

10. Barthel A, Gourinat AC, Cazorla C, Joubert C, DupontRouzeyrol M, Descloux E. Breast milk as a possible route of vertical transmission of dengue virus? Clin Infect Dis. 2013;57(3):415-7. DOI: http://dx.doi.org/10.1093/cid/ cit227

11. Kuhn S, Twele-Montecinos L, MacDonald J, Webster P, Law B. Case report: probable transmission of vaccine strain of yellow fever virus to an infant via breast milk. CMAJ. 2011;183(4):243-5. DOI: http://dx.doi.org/10.1503/ cmaj.100619

12. Sedgh G, Singh S, Hussain R. Intended and unintended pregnancies worldwide in 2012 and recent trends. Stud Fam Plann. 2014;45(3):301-14. DOI: http://dx.doi. org/10.1111/j. 1728-4465.2014.00393.x

13. Musso D, Roche C, Robin E, Nhan T, Teissier A, CaoLormeau VM. Potential Sexual Transmission of Zika Virus. Emerg Infect Dis. 2015;21(2):359-361. DOI: http://dx.doi. org/10.3201/eid2102.141363

14. Mansuy JM, Dutertre M, Mengelle $C$, et al. Zika virus: high infectious viral load in semen, a new sexually transmitted pathogen? Lancet Infect Dis. 2016;16:405. DOI: http:// dx.doi.org/10.1016/

15. Cao-Lormeau VM, Blake $A$, Mons $S$, Lastère $S$, Roche $C$, Vanhomwegen J et al. Guillain-Barré Syndrome outbreak associated with Zika virus infection in French Polynesia: a case-control study. Lancet. 2016;387:531-1539. DOI: http://dx.doi.org/10.1016/S0140-6736(16)00562-6

16. Organización Panamericana de la Salud (OPS). Vigilancia de virus Zika (ZIKV) en las Américas: Recomendaciones provisionales para la detección y diagnóstico por laboratorio. Washington D.C; 29 de junio de 2015. (Fecha de Consulta: Feb 24, 2016). Disponible en: http://bit.ly/1SHFcdn

17. Petersen EE, Staples JE, Meaney-Delman D, et al. Interim Guidelines for Pregnant Women During a Zika Virus Outbreak - United States, 2016. MMWR Morb Mortal Wkly Rep. 2016;65(2):30-33. DOI: http://dx.doi.org/10.15585/ mmwr.mm6502e1.

18. Jenco $M$. CDC releases guidelines on preventing sexual transmission of Zika, testing pregnant women. AAP News. February 5, 2016.

19. Vouga M, Musso D, Mieghem TV, David-Baud D. CDC guidelines for pregnant women during the Zika virus outbreak. Lancet. 2016;387:843-844.

20. Hills SL, Russell K, Hennessey M, et al. Transmission of Zika Virus Through Sexual Contact with Travelers to Areas of Ongoing Transmission-Continental United States, 2016. MMWR Morb Mortal Wkly Rep. 2016;65(8):215-216. DOI: http://dx.doi.org/10.15585/ mmwr.mm6508e2.

21. Secretaría De Salud. Acuerdo por el que se determinan las sustancias prohibidas y restringidas en la elaboración de productos de perfumería y belleza. Diario Oficial. 2a Edición. México 2010. (Fecha de Consulta: $1^{\circ}$ de marzo 2016) Disponible en: http://www.cofepris.gob.mx/MJ/ Documents/AcuerdosSecretario/salud21may10.pdf.

22. Adelman ZN, Tu Z. Control of Mosquito - Borne Infectious Diseases: Sex and Gene Drive. Trends Parasitol. 2016;32(3):219-29. DOI: http://dx.doi.org/10.1016/j. pt.2015.12. 003

23. Centers for Disease Control and Prevention (CDC). Zika virus symptoms, diagnosis, and treatment. 2016. (Fecha de Consulta: Feb 24, 2016). Disponible en: http://www. cdc.gov/zika/symptoms/index.html.

24. Centers for Disease Control and Prevention (CDC). Mensajes claves sobre la enfermedad por el virus del Zika. Para Uso Externo. 24 de febrero 2016. (Fecha de Consulta: 1을 marzo 2016). Disponible en: http://www.cdc.gov/zika/es/ pdfs/spanish-key-messages.pdf 